\title{
Essential(ist) medicine: promoting social explanations for racial variation in biomedical research
}

\author{
Iliya Gutin
}

Department of Sociology, University of North Carolina at Chapel Hill, Chapel Hill, North Carolina, USA

\section{Correspondence to}

Mr lliya Gutin, Department of Sociology, University of North Carolina at Chapel Hill, Chapel Hill, NC 27499, USA; igutin@live.unc.edu

Accepted 30 May 2018 Published Online First 25 June 2018
Check for updates

To cite: Gutin I.

Med Humanit

2019;45:224-234.

\section{ABSTRACT}

Biomedical research has a long and complicated history as a tool of oppression, exemplary of the racial science used to legitimise and maintain racial hierarchies in the USA and abroad. While the explicit racism and racial inferiority supported by this research has dissipated and modern methods of inquiry have increased in sophistication and rigor, contemporary biomedical research continues to essentialise race by distilling racial differences and disparities in health to an underlying, biogenetic source. Focusing on the persistence of essentialism in an era of genomic medicine, this paper examines the deep social origins and social implications of the essentialist viewpoint in biomedicine and how it relates to the broader construction of social and scientific knowledge. Invoking Hacking's 'looping effects' as a useful conceptual tool, I then demonstrate how sociohistorical forces influence scientific and medical research in producing evidence that favours and legitimises a biological construction of race. I extend the looping framework to consider a parallel 'louping' process whereby applying a socially rooted meaning to race in biomedical research results becomes magnified to influence social norms and ideas about race. As many biomedical researchers are motivated by a desire to eliminate racial disparities in outcomes, I argue that greater social acuity allows scientists to avoid individualising and racialising health, challenge preconceived assumptions about the meaning of racial variation in health and medicine and thus promote and strengthen a socioenvironmental focus on how to best improve individuals' and population health. Concluding with a call for structural competency in biomedical research, I suggest that empowering scientists to more freely discuss sociostructural factors in their work allows for the continued use of race in biological and medical research, while social scientists and medical humanities scholars stand to benefit from seeing their work imbued with the cultural authority currently granted to biomedicine.

\section{INTRODUCTION: BLOOD, BIOGENETICS AND THE MEANING OF BLACKNESS}

Recent decades have seen considerable growth in both the quantity and scope of social and medical research documenting racial differences in the health of the US population, primarily between White and Black adults. ${ }^{1}$ Even the language used to define these differences has expanded, such as the emergence and proliferation of terms like health 'disparities' and 'inequities' during the 1990 s. $^{2}$ Despite this increase in both interest and terminology, the real and substantial racial gaps in health that this research describes are not a modern development. Over 350 years of American history, from the institutionalisation of slavery through the systemic racism and discrimination still prevalent in a post-Civil Rights era, provides a continuous narrative of the sociopolitical mechanisms creating and maintaining racial inequalities in health across a broad spectrum of conditions: longevity, infant health and mortality, immunisation, exposure to toxins, HIV, mental health and chronic disease morbidity and mortality, to provide a very broad overview. ${ }^{34}$ Even now, in an era marked by progress in both public health and medical innovation, BlackWhite disparities are persistent across a number of health domains, ${ }^{5}$ while some speculate these gaps will only widen in the years to come. ${ }^{6}$

However, the nascence of this historical association between race and health can be traced at least back to the point of first contact between the White explorers of mainland England and the Black natives of the African continent, when race-based aspersions concerning the latter group's health and overall physical/mental well-being were already being cast. Seeking an explanation for the skin colour of these newly encountered 'savage' and 'heathen' peoples, the English found answers in the form of quasi-scientific and medical rationalisations of dark skin as a marker of innate unhealthiness. More than a phenotypic trait, 'blackness' was the product of the sun having 'scorched the skin, drawn the bile or blackened the blood'; it was a divine form of 'natural infection', immutable and intergenerational. ' Blood-rather, the corruption of blood-was central to this narrative given scientific and medical consensus on its status as a life-giving, elemental substance (eg, 'the vital juice of life ${ }^{8}$ ), with disease originating in the 'dregs of the blood' itself. ${ }^{8}$ Consequently, Black blood was contaminated blood-tainted, tarnished, darkened and dirty, and a direct indictment against the competence and health of the Black race as a whole, especially compared with the 'unblemished' dominant White population.

Though our preoccupation with blood has faded, and the scientific understanding of health has evolved, there remains a persistent interest in attributing a biological origin to racial differences and disparities in health and, increasingly, medicine. The methods used in this pursuit have advanced considerably; the rapid advancement of scientific knowledge and technology has shifted attention to genetic entities (such as single nucleotide polymorphisms (SNPs), haplotypes, mitochondrial and autosomal DNA) as the 'fundamental' building blocks of race and health. The cultural, historical, 
social, political and economic environment in which research is conducted and knowledge is created has been transformed as well; the explicit racism underlying the historical oppressions of Blacks, and the corpus of biological and medical science legitimising these beliefs, has been supplanted by federal and financial incentives emphasising the inclusivity and individuality of Black participants in research. ${ }^{10-12}$ Consequently, researchers' intentions motivating this pursuit have shifted; rather than seeking to portray Blacks as a biologically inferior and sicker race, contemporary biomedical researchers frame their work as a tool for social justice by using scientific knowledge to target racial health disparities at the molecular and genetic level. ${ }^{13}$

However, the core premise of this biomedical research agenda remains unchanged. Despite calls for an improved conceptualisation of race in biomedical research, scientists continue to adopt an 'essentialist' framework in interpreting the significance of race in their work by imbuing the same centuries-old, phenotypically informed and socially constructed categories of race with genetic meaning. ${ }^{14} 15$ These decisions are consequential given biomedicine's vantage point at the intersection of race, genetics and medicine, where scientists translate assumptions about racial differences in genetics into 'personalised' medical treatments and validate scientific and public beliefs about race as a biological rather than social identity. While this research seeks to explore and test biogenetic mechanisms underlying health, the resulting pharmaceuticals and biomedical interventions are disseminated without a definitive understanding of both 'intrinsic' (ie, genetic, physiological and pathological) and 'extrinsic' (ie, socioeconomic background, culture, diet and environment) factors shaping their race-specific efficacy. ${ }^{16}$ Yet, any residual or unexplained racial heterogeneity in treatment effect continues to be framed as intrinsic; an assumption that has broader consequences detrimental to socioenvironmental efforts in reducing the same racial health disparities targeted by biomedical research. ${ }^{17-22}$

Challenging the essentialist treatment of race in biomedical research, this paper draws on a large body of sociological, anthropological and historical research to emphasise the social origins and implications of how we understand racial variation in health and medicine, and how this relates to the broader, mutually constitutive relationship between social and scientific knowledge. I begin by reviewing the sociohistorical shift from explicitly using racial disparities in health and medicine to establish and maintain racial hierarchies, to a recent focus on pharmacogenomics and 'racially tailored' medicine implicitly promoting a similar racialised framework for understanding health. I then discuss the contemporary practice of essentialising race, highlighting its prominence as a variable in biomedical research and how its role as a proxy for biogenetic differences becomes engrained in expert and lay knowledge.

In search of solutions to this ongoing reification of race as a biogenetic entity, I turn to Ian Hacking's 'looping effects' framework ${ }^{23}$ arguing that biomedical researchers are uniquely positioned to promote a social rather than biogenetic interpretation of racial variation in their work, helping dispel the essentialist framing of racial health disparities. Drawing on qualitative work in this area, I emphasise social and biomedical scientists' shared goal of racial justice and improving population health through the elimination of racial disparities, although informed by different research paradigms and disciplinary norms. This leads me to conclude with a call for greater structural competency in the biomedical field, whereby biomedical researchers are empowered to present socioenvironmental factors as mechanisms underlying racial variation in individuals' presentation of disease or response to medicine. In exchange, the social sciences can leverage the cultural authority of biomedicine to advance social explanations and solutions for health disparities, demonstrating how billions of dollars in research and development, and the most cutting-edge biomedical innovations, are no panacea for the long-standing legacy of racial health inequality.

\section{RACIAL SCIENCE PAST AND PRESENT}

Not unlike the construction of scientific knowledge, with present work building on an extant and growing body of research, the sociohistorical context for the continued essentialisation of race in biomedical research is the result of a cumulative, centuries-long account of race and health socially intertwined concepts. As prefaced earlier, the contemporary attribution of genetic origins to racial health disparities is best understood as only the latest iteration of scientific racism, that is, the well-documented legacy of scientists and medical practitioners using their authority to promote, maintain and legitimise racism and the group-based categorisation of humans. ${ }^{24}$

\section{Inferiority and oppression}

History provides many examples of the varied sources used to promote biological differences among races-based on anatomy, physiology and mental faculties-such as writings from antiquity, 'natural scientists' endless and largely fictional catalogues of racial traits' and biblical scholarship all informing scientific and medical theories of Black health. ${ }^{10}$ Even historical ideals of beauty, as reflected in art and literature, were imbued with 'medical' significance; the social desirability and 'purity' of White skin on canvas and in print served as a proxy for the superior strength and vitality of the White race. ${ }^{25}$ Working in tandem, these scientific and cultural forces identified racial disparities in health within individuals rather than their social environments. Favouring 'naturalistic' explanations of non-white racial inferiority in matters of health, the consistent neglect of socioenvironmental influences was integral to promoting a 'blame the victim approach... with no systematic, logical, or rigorous scientific methods to test [these] theories' of innate inferiority. ${ }^{10}$

Dispelling the aura of objectivity surrounding scientific and medical thought is key to understanding the persistence of racial science. As Harriet Washington notes, 'the science of race has always been an amalgam of logic and culture', and race itself 'is an important but nebulous and shifting facet of scientific medical thought', ${ }^{10}$ such that the prevailing theories defining race in a given era-ranging from Greek thought on environment and temperament, to Linnaean concepts of taxonomy and differential evolution, to White supremacist ideologies of Black inferiority - give rise to medical practice and scholarship further reinforcing these beliefs. More to the point, medical research has been consistently deployed as a tool of oppression and a large body of scholarship in the history of medicine and social studies of science documents the many ways in which non-White bodies have been manipulated to legitimise, quantify and preserve the racial hierarchy. ${ }^{105-29}$

Most representative of this manipulation is the forcible and/ or misleading recruitment of Black adults for scientific experimentation, often premised in a desire to prove the innateness of racial differences in health and disease rather than to objectively question these assumptions. Using crude intelligence tests and the faux-science of craniometry to demonstrate intellectual inferiority, coupled with assumptions about an innate 'hardiness' that enabled survival and work in harsh climates, early racial science rationalised slavery and manual labour as optimally suited 
for Black bodies. ${ }^{10}$ However, the notion that Blacks have any physiological 'advantages' was soon replaced by pity and inferiority, premised on medical experimentation identifying 'black diseases' and mental illness (having either entirely imaginary or entirely social aetiologies). Under this framework, slavery and the artificial concern for Black well-being provided a way for Whites to simultaneously 'care for' Blacks-in providing the barest of food, shelter and work-and also be 'protected from' Blacks-either through their enslavement or racial segregation. ${ }^{10}$

Though slavery provided a convenient rationale for legitimising Black inferiority, the focus of early 20th century racial science and medicine sought to frame Blacks as a uniquely diseased race, inferior to Whites and 'too delicate to survive'. ${ }^{10}$ The medically manufactured idea of 'bad blood' was emblematic of this effort. Rather than a discrete disease or health condition, doctors framed the condition as an imprecise cluster of physical and mental ailments and symptoms somehow unique to Black adults, especially men. However, as extensively covered in the work of Allan Brandt and James Jones, the 'bad blood' of Black men was an easily diagnosable and curable form of syphilis, whose treatment was withheld in an effort to validate assumptions about that the same disease presenting differently among Blacks than Whites. ${ }^{26} 27$ Critically, the Tuskegee Syphilis Study, and the numerous other instances of callous and unethical experimentation with Black bodies, ${ }^{30}$ demonstrates how medical research helps to maintain a racial hierarchy; framing racial health disparities as originating within the body contributes to narratives of inferiority on the basis of innate differences. In turn, this medically validated physical and mental inferiority was used to justify the subjugation of dark-skinned individuals, across numerous historical and geographic contexts. ${ }^{28}$ Evident from this historical and anthropological work is the degree to which scientific medical research is quickly marshalled to change the meaning and origins of poor health among Blacks in support of changing social rationales and contexts for White supremacy.

\section{Inclusion and (financial) opportunity}

Only recently in the scope of the medical and racial history of the USA has the explicitly racist framework for biomedicine been replaced by a new framework of 'inclusion' and equality. Driven by recognition of past racial injustice in science, the advancement of civil rights and the persistence of racial disparities in health, this crucial shift in intentionality among researchers represents an example of social and cultural forces seeking to positively shape scientific knowledge. ${ }^{11}$ Combatting past discrimination, many leading government and regulatory agencies overseeing biomedical research (eg, National Institutes of Health (NIH), Federal Drug Administration (FDA)) have instituted diversity recommendations and/or mandates for funded projects. As discussed by Steven Epstein and others, the NIH Revitalization Act represents the pinnacle of this movement with its explicit requirement for the inclusion and representation of multiple racial and ethnic groups in research, whereon the onus on researchers is to justify why their studies would not require a racially diverse sample, at the risk of losing funding or receiving a poor evaluation. ${ }^{1130-32}$

The drive for inclusion has gained momentum given the attention and excitement surrounding individualised medicine and treatment as the future of healthcare and delivery and a pathway to address racial disparities in health. Often called personalised or genomic medicine, it constitutes a 'rapidly advancing field... informed by each person's unique clinical, genetic, genomic, and environmental information', 33 made possible the by the falling cost and increasing availability of genetic testing. ${ }^{34}$ Many scholars have argued on behalf of 'accelerating' the translation of human genome research into tangible, medical treatment that can benefit patients in numerous ways. ${ }^{35-39}$ The most promising manifestation of personal medicine is the emergence of pharmacogenics, studying heterogeneity in individuals' responses to medicine in an effort to design 'magic bullet' drugs uniquely tailored patients' needs. ${ }^{40}$ Assuming that better knowledge of the human genome will lead to better and more precise medicine that targets the biogenetic roots of disease, ${ }^{41}$ biomedical research has sought to target individuals — or groups of individuals, on the basis of some shared genetic, racial ancestry-with customised drugs and treatment protocols. Towards this end, having more racially diverse and inclusive research samples engenders a greater diversity of biomedical solutions.

The intention behind inclusion mandates, and the personalised medical research they are intended to support, is noble; given the well-documented racial variation in the efficacy of medical treatment, greater diversity can begin addressing racial disparities during the research and development process. Yet many scholars argue that the growth of biogenetic research coupled with social, economic, regulatory and legislative pressures has given rise to a form of colour-blind racial science; the phenotypic differentiation of race (ie, skin colour) has been replaced by genotypic variation in biomedical research. ${ }^{29}$ Inclusionary policies presume a priori that racial differences exist and thus encourages the search for these disparities with no clear theory or expectation of the importance of race or underlying causal mechanisms. ${ }^{11}$ Consequently, any observed racial differences are interpreted as genetic rather than socioenvironmental, further essentialising race as a biological, rather than socially constructed, category. ${ }^{42-44}$

The role of market-driven forces perpetuating 'colour-blind' biomedical research cannot be overlooked either. Pharmaceutical and clinical research are profit-driven, multibillion dollar industries, whose substantial investments in creating medical treatments come with an expectation of even greater returns. As seen with pharmacogenomics and the surge of 'racially tailored' drugs, this return-on-investment model favours the identification of group differences in medical efficacy, as the 'niche marketisation' of products aimed at specific racial groups effectively multiplies the number and diversity of drugs that can be sold. ${ }^{1145}$ Though the burgeoning field of 'personalised' medicine implies a focus on individuals, terms like 'uniquely tailored' and 'whole-genome approach' overstate the current ability of biomedicine to craft solutions catered to the needs of a single person. ${ }^{46}$ Instead, the resulting compromise is a new middle-ground-or 'middle-level'11_ where groups of similar individuals are the target of biomedical research, rather than the individuals themselves.

For instance, as Jonathan Khan demonstrates in his analysis of BiDil's marketing and development as a drug for congestive heart failure in African-Americans, genomic and biomedical data can be manipulated to produce racial differences in the effectiveness of medical treatment, thus improving marketability and profitability. ${ }^{12}$ Specifically, a confluence of media, legal and political forces, and the growth of social and scientific faith in genomic research, allowed racial disparities in heart failure mortality to become reified as evidence of genetic differences in racial responses to medical treatment, paving the way for BiDil as a 'black drug'. Nearly 30 different medications have been designed to target racial variation in efficacy, though systematic reviews did not find evidence to substantiate a majority of the 
biogenetic causal mechanisms underlying these claims. ${ }^{i} 47$ Lee refers to this misappropriation of race in pharmacogenomics as a product of the 'infrastructure of racialisation', where pre-existing conceptions of racial variation in the human genome, epidemiologic and clinical data of racial health disparities and market forces encouraging group-specific specialisation, collectively promote race-based medicine as successful in targeting true biogenetic, racial differences within the population. ${ }^{22}$

Despite this critical portrayal of inclusionary politics in biomedical research, the push for diversity should not be misconstrued as a wayward pursuit of political correctness by biomedical researchers or an overcorrection for the past mistakes of racial science. Rather 'inclusion' is the product of an uncritical perspective on race and the significant role of science as a social institution creating knowledge further essentialising race; as more diseases and conditions are linked to race, and as more race-specific medicines cater to these diseases and conditions, race assumes greater medical significance and is further crystallised as a biological construct. Some have argued that beyond 'racialising' disease, biomedical research has been used to 'create' racialised diseases themselves, such as the promotion of 'metabolic syndrome' as a cluster of health conditions especially prevalent among Black adults. ${ }^{29}$ Clearly then, biomedical researchers' own understandings of race have far-ranging social implications as well. While the above-described inter-relationship between sociopolitical factors and scientific practice helps establish a broader framework for the essentialisation of race throughout history, in the following section I narrow my focus to consider how race is understood and used within the biomedical community.

\section{ESSENTIALISING RACE}

Although the biomedical paradigm of research and knowledge is defined by a high degree of standardisation in its measures and definitions, ${ }^{1148}$ the rapid pace of change in the collection, sequencing and incorporation of genetic data in research has stimulated debate over the conceptualisation and use of race in contemporary biogenetic medicine. These definitional arguments fall along a spectrum, with definitive genetic origins on one end and pure social constructionism on the other, but the permutations and mixtures of these two polarities result in a dense continuum of perspectives on the issue. ${ }^{43}{ }^{49-53}$ Much of the work examining the ethical and practical implications of race has instead asked whether any conceptualisation of race in medicine is appropriate or necessary, ${ }^{54-57}$ especially when the social and genetic definitions of race are associated with contradictory health outcomes. ${ }^{20}{ }^{21}$ While I do not purport to resolve this issue at present, I raise the point to emphasise that amid the debate regarding the definition of race and with its use and measurement often unquestioned and largely unstandardised, ${ }^{58-60}$ an essentialist view of race remains dominant in biomedical research.

\section{The present state of race}

The majority of current academic and clinical work in biomedicine implicitly essentialises race by treating it as a proxy for a myriad of potential genetic and/or biological traits underlying health and disease. ${ }^{\text {ii }} 32424461$ This default assumption is sufficiently prevalent that a lack of significant racial differences is often reframed as an issue of statistical power; researchers argue that differences are small rather than non-existent. ${ }^{31} 42$ Many in the health, medical and social science communities have challenged this commonplace understanding of race as undertheorised and misleading in its continued reification of race as a biological entity. ${ }^{42-64}$ In a review and critique of race variables in genetic studies, Shields et al note a lack of 'constructive interdisciplinary dialogue' in the design and implementation of race measures, and numerous logical fallacies committed by geneticists who ignore a 'long social history of destructive uses of racial categories in science and medicine', by arguing that there is no 'value system' inherent to findings associated with race. ${ }^{65}$ While conceding that geneticists have largely abandoned the search for racial typologies in the human genome, Foster and Sharp note a continued reliance on associating 'biological findings with the social identities of research participants', thus using genetic features to 'reconstruct' population histories and 'redefine' commonalities as genetically immutable. ${ }^{66}$

Ultimately, critics of this uncritical use of race and/or ethnicity in biomedicine push for a 'new vocabulary' facilitating the unbiased inclusion and testing of bioancestral variation. ${ }^{6768}$ Though the hope is these 'improved' measures and definitions of race would help to avoid the danger of biogenetic data being used to reaffirm 'old prejudices' of perceived differences and similarities among individuals, ${ }^{69} 70$ there is concern that current approaches for redefining race as a continuous rather than discrete measure (eg, "clinal classes ${ }^{, 71}$ ) are prone to the same biases of insinuating a biological basis for race. ${ }^{72} 73$

\section{The 'stickiness' of essentialism}

Importantly, these dynamic yet consistently essentialist views of race-and the biomedical researchers who rely on them-do not exist in a sociohistorical vacuum. Scientific knowledge is imbued with significant cultural authority and power in society, informing social understandings, beliefs and norms regarding race. Research with simple vignettes about race as either a biological or social construct consistently demonstrates that lay individuals internalise and rely on scientific and biomedical knowledge in informing personal views on the origin of race and its implications for health. ${ }^{74-76}$ Analyses of news reports in recent years, with a focus on the presentation and language used to describe scientific research on race and health, uncover an upward trend in the discussion of race-specific diseases and framing of race as a risk factor for disease, supporting Troy Duster's prescient warning that the modern biogenetics movement may provide a 'backdoor to eugenics' in its reification of race as biological and consequential to health. ${ }^{74}$

The process of normalising race as an essentialist construct is not exclusive to the formation of lay knowledge about race, genetics and health; researchers are not immune to similar messages and cues about race in their environment and training. Despite increased recognition of race as socially constructed, and social scientists' assumptions about the positive uptake of this belief in the natural sciences, research suggests that this constructionist viewpoint is not highly prevalent. ${ }^{77}$ Indeed, there is ample sociological and anthropological evidence to suggest that narratives and framing surrounding race as a biological concept are created and reinforced at multiple points in the acquisition and formalisation of biomedical knowledge.

Empirical work in recent years-most notably studies conducted among biomedical researchers and students ${ }^{15} 78$ and through analysis of their materials ${ }^{79} 80$-reveals a latent 'stickiness' or tendency towards essentialism in the institutions and knowledge resources that researchers use to gain expertise. Throughout interviews conducted with students, faculty and researchers at leading universities, Ann Morning notes the many obstacles impeding the penetrance of non-biological 
understandings or race in biological research. Given the hierarchical power dynamics in academia-such as between instructors and students or principal investigators and research assistants - traditional and essentialist definitions of race held by more senior scholars remain dominant and thus become adopted by more junior researchers. ${ }^{15}$ Even if biologists are exposed to anthropological, socially based definitions of race, the inability to see these definitions applied in a biomedical research or classroom environment contributes to a reversion to existing, biologically based thinking. ${ }^{15}$ For instance, journals and other outlets for scientific knowledge continue to prioritise genetic interpretations of race in publications and avoid challenging researchers to be more critical in their use of race. ${ }^{8182}$ Studies have also shown how the mandated inclusion or careful attention paid to race in scientists' proposals is often absent in subsequent publications and reports. ${ }^{31}$ Most troublingly, while content analysis of textbooks and other 'repositories of knowledge' used by biologists, clinicians and biomedical researchers notes change in the definition of race over time, ${ }^{79} 80$ 'the fundamental message about the nature of race has changed little' and, if anything, 'the overall impact of genetics has been to bolster, rather than challenge' an essentialist view. $^{79}$

An important takeaway from this work is that reminding the biomedical community to entertain the idea of race as a 'social construct' proves insufficient. A lack of knowledge or awareness about non-essentialist views of race is not at issue; scientists acknowledge the existence of socially constructed definitions of race and some actively engage in 'antiessentialism', though without entirely conceding that race has no biological basis. ${ }^{77}$ The more salient obstacle to adopting constructionist views of race is a set of beliefs suggesting that: social explanations for race are incompatible with the methods and knowledge in biomedical research; explaining racial variation through social mechanisms is beyond the purview of biomedicine and genetics and that the social and biological sciences simply rely on different definitions of race that are most conducive to their research. ${ }^{32} 83$

Chronicling the difficulties in teaching race to medical students, Warwick Anderson captures all three processes at work in students' resistance to a constructivist interpretation of race on the basis of concerns over 'credibility' and beliefs about who among social and biological scientists is best-equipped to define race. ${ }^{78}$ In interactions with students and instructors representing both the anthropological and biogenetic perspectives on race and health, most apparent are firm disciplinary guidelines favouring specific definitions of race enforced by explicit curricula and implicit norms. Medical students and geneticists-lacking formal instruction or significant exposure to social sciencesfeel they are not in a position to evaluate the validity of race as a social construct, let alone apply it in their work. They are equally prone to question social scientists' authority in arguing against the biological basis of race, given their lack of biogenetic training. In turn, social scientists' arguments about the problematic nature of essentialist views on race fail to resonate, as they are incompatible with medical students' and geneticists' views that this essentialism instead helps dispel racism by valuing individualism and that understanding racial genetic variation is the key to addressing health disparities. ${ }^{78}$

\section{A MORE 'SOCIAL' SCIENCE}

As evidence shows, imposing a constructivist framework for race on biomedical research is encumbered with a number of obstacles: the current use of race in biomedical research does not support this definition; social mechanisms and solutions are not the focus of biomedical research and knowledge and biomedical research bears no social responsibility for how race is understood by the public. However, social scientists are right to be concerned about biomedicine's role in propagating the idea of races as different 'natural kinds' of humans that can be categorised and ordered. ${ }^{23}$ Essentialising any human trait, independent of race, allows for its uptake as a salient aspect of individuals' identities. Yet the growing biogenetics movement in health raises concerns about individuals' taking on distinct 'biosocial' identities, where the 'bio' component is rooted in a shared predisposition to disease and/or response to medical treatment. ${ }^{84-86}$ Given the strong relationship between race and health driven by sociostructural factors, biosocial identities are liable to hue closely to extant racial groupings in society and further substantiate essentialist views of race.

Seeking to avoid this backslide into redefining race on the basis of health and disease, I contend that a push for greater social acuity needs to emerge from within the biomedical community. Towards this end, in the following sections, I outline an argument for better defining the role and contribution of biomedical research to the production of social knowledge about racial disparities, emphasising the capacity for biomedical researchers—as scientific actors with 'agency'—to catalyse social and scientific change in views on race.

\section{Loops becoming loupes}

Among the many theories and frameworks describing how scientific knowledge becomes social, Ian Hacking's concept of 'looping effects' in the natural and clinical sciences proves to be a powerful tool for understanding the critical role of biomedical researchers in subverting essentialist views of race. Hacking's analysis of sociohistorical trends in the changing classifications of individuals (or a 'kind of person that is a moving target ${ }^{23}$ ), often on the basis of their physical and mental health (eg, multiple personality disorder, autism, obesity), reveals a sustained and recurring pattern where: (1) a new scientific classification is established; (2) people meet the criteria for said classification; (3) institutions formalise the classification; (4) knowledge is established in the form of 'presumptions that are taught, disseminated, refined and applied within the context of institutions' and (5) finally, experts create and legitimise this knowledge through their work. ${ }^{23}$ Rather than purely a sequential process, the 'looping' aspect of this framework describes the reciprocal process by which experts' work is channelled back towards solidifying and reifying these classifications.

While Hacking is cautious about applying this framework to race (or gender or other socially and historically embedded categories), he acknowledges its utility in ongoing debates surrounding the 'scientific' basis for race in contemporary research. ${ }^{87}$ For the purposes of this argument, the applicability of the looping framework to the use of race in biomedical research-rather, the theory underlying its use-is worth illustrating. As seen with the concentric circles in figure 1, biomedical research interfaces with the looping process at every stage: (1) classifying the origins of race as a risk factor for health and disease; (2) identifying the race(s), and thus individuals, having the greatest risk on the basis of these origins; (3) institutionalising concepts of race, health and underlying mechanisms; (4) producing biomedical knowledge or basic 'facts' about race and health and, finally, (5) providing the experts and arbiters of knowledge that create and interpret the role of race in their research settings. Critically, the looping framework situates biomedical researchers at the fulcrum of this process, as both 


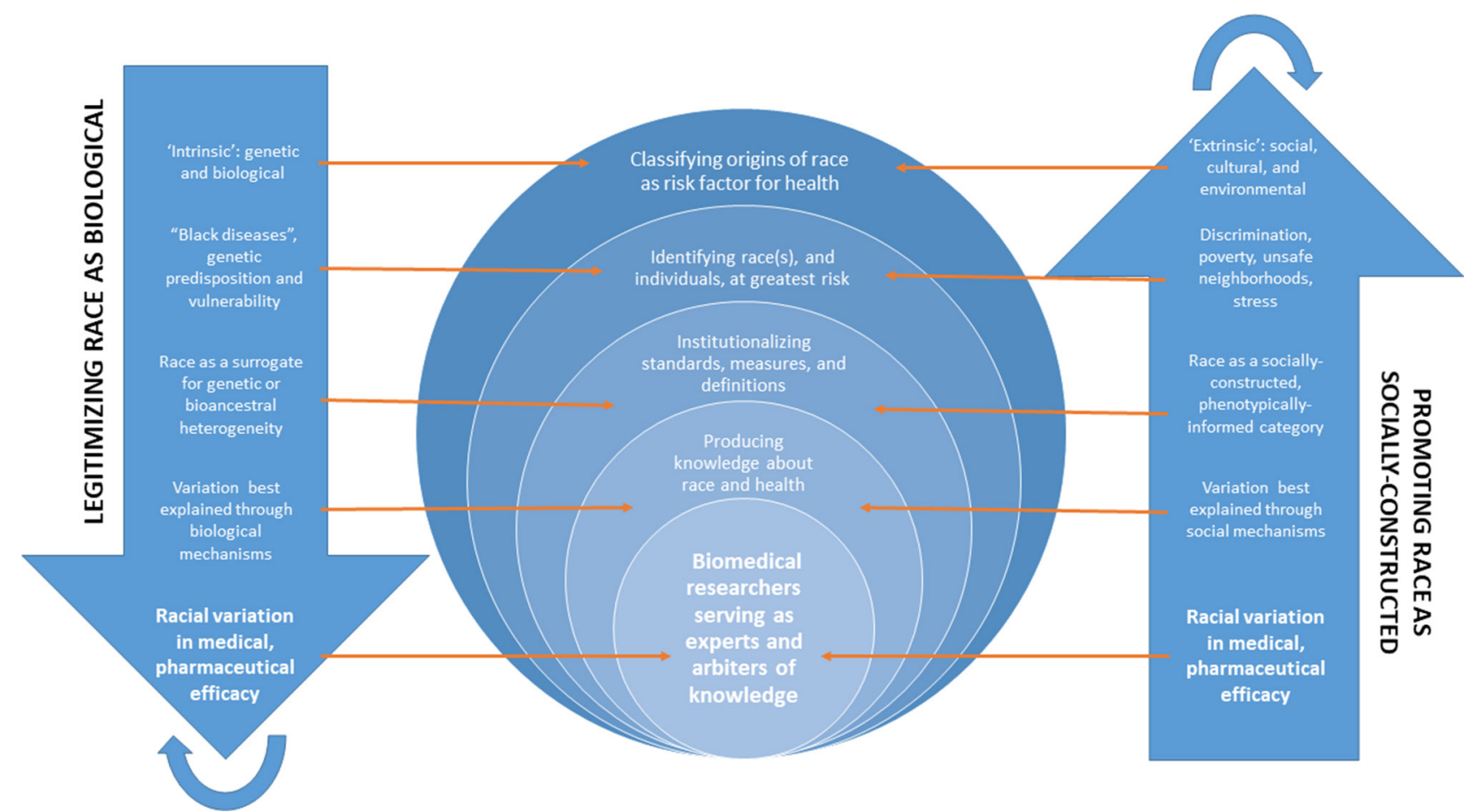

Figure 1 The looping and 'louping' of race in biomedical research.

shaping and shaped by prevailing social and scientific ideas concerning the aetiology of race.

Following the 'top-down' version of this framework, as indicated by the left-hand arrow, societal-level norms and assumptions about the relationship between race and health as defined by 'intrinsic' (ie, genetic and biological) mechanisms are observed at multiple levels. Consistent with the prior discussion of sociohistorical processes helping to preserve an essentialist view of race, the presupposition of race as a biogenetic concept propagates the identification of 'Black diseases' and other genetically linked health conditions among Black individuals, which then reinforces the definition and use of race as a surrogate for genetic heterogeneity (such as within the NIH). This widespread use of race as a genetic proxy sustains the belief (and knowledge) that observed racial variation in health or response to medicine is attributable to biological differences. Thus, if and when biomedical researchers uncover racial variation in medical efficacy, their default interpretation of the results both confirms and reaffirms an essentialist view on race. In this manner, the looping framework provides a clear narrative of how biological and sociocultural notions (and definitions) of race inform one another and, critically, contribute to an overall reification of race as a category. Through this looping process-backwards and forwards, and over time-races indeed become 'natural kinds' or biosocial identities on the basis of shared and innate predispositions to disease or poor health.

However, I contend that this looping schema can instead be deployed to situate biomedical researchers as 'agents of change', positioned to promote a more socially conscientious view of race in health and medicine. As demonstrated by the right-hand arrow in figure 1, the looping creation of scientific knowledge has the capacity to become a 'magnifying loupe' through which the individual-level decisions of biomedical researchers expand outward in the knowledge creation process to challenge social-level essentialist thinking on race. The same discovery of 'unexplained' racial variation in the efficacy of a biomedical intervention can be framed as a function of social mechanisms, to the extent that the standard categories of race used by biomedical researchers reflect different social realities among study participants. Moving upward through the framework, such an explanation calls for a socially constructed basis for the definition and use of race in research, and instead identifies risk as originating in the disproportionate levels of discrimination, poverty and stress experienced by Blacks. Recognition of these social determinants of health, and their influence on biomedical research, can reorient scientists' views on race and medicine as driven by 'extrinsic' mechanisms, which are primarily social, cultural and environmental. Reversing this 'louping' framework, the adoption of macrolevel constructionist views on race can inform the microlevel decisions of future biomedical researchers in their interpretation of race-based findings.

Importantly, this framework emphasises that epistemological change does not occur all at once; a single researcher's or lab's decision to focus on social factors contributing to racial variation in drug efficacy is unlikely to have a meaningful impact at a given point in time. Nor would the decision of a single journal or funding agency to have researchers more adequately control for socioenvironmental factors reverse decades of education, training and scholarship reinforcing an essentialist view. Instead, the twin processes of looping and 'louping' allow for gradual and sustained challenges to essentialism-such as biomedical researchers increasingly citing evidence from the social sciences and medical humanities in their work- to continually re-enter the knowledge production chain and become magnified and amplified over time, with the goal of gaining sufficient momentum to legitimise of a constructivist position on race in science. The importance of momentum is entirely consistent with grand theories of epistemological change often used to describe scientific research; new and improved evidence increasingly challenges existing theories until enough evidence accrues to substantiate a paradigmatic, discipline-wide shift in theory. ${ }^{88}{ }^{89}$ Likewise, given the embeddedness of essentialism in contemporary 
biomedical science, we should expect that a broader recognition of socially driven racial differences in medicine will be slow and cumulative rather than acute and revolutionary.

\section{Well-intentioned medicine}

In recognising the importance and confounding influence of social determinants in their work, biomedical researchers must remain vigilant to avoid the creation and perpetuation of knowledge that undermines a socially based approach to addressing racial health disparities. The associations among race, disease and medical efficacy are important to identify and have clear social and scientific utility; but clarity and transparency with respect to the specification of mechanisms at work is critical as well. In many cases, race takes on the value and meaning of leftover variation 'unaccounted for' or 'unexplained' by the existing set of variables in analyses; that is, the hypothesised biogenetic mechanisms sought by science. ${ }^{32}$ Yet biomedical research is governed by a paradigm of knowledge that seeks to eliminate uncertainty and provide concrete answers or scientific 'truths'. ${ }^{85}$ Thus race becomes a way to avoid conceding a lack of a definitive understanding of the role of genetics and biology in explaining racial variation in health and medical research.

Kahn, ${ }^{12}$ Epstein ${ }^{11}$ and Braun ${ }^{44}$ all raise the issue of how this 'in the meantime' use of race contributes to the ongoing reification and essentialisation of race. In suggesting that future scientific advances will validate the biogenetic origins of race, the 'temporary' geneticisation or biologisation of race nonetheless provides an objective, scientific basis that informs and biases current and future research. ${ }^{114}$ Thus, beyond redefining race as a socially constructed variable, biomedicine must also put this knowledge into practice by acknowledging that observed racial variation is equally liable to capture the social consequences of individuals' race and how they influence medical efficacy. Even when biomedical researchers avoid making explicit proclamations about the biogenetic origins of race or racial variation in outcomes, ${ }^{42} 61$ a failure to offer an alternative explanation for observed differences allows for the idea that race might be grounded in some objective, biological reality to fill this vacuum of meaning.

However, researchers' intentions to explain away racial differences represents more than compliance with the biomedical paradigm's aversion to uncertainty. In contrast to the past history of racial medical science, I believe it is necessary to emphasise that the contemporary racialised framing of biomedical research is fundamentally motivated by the researchers' desires to eliminate racial health disparities. In this era of 'well-intentioned medicine', the most sophisticated, promising and cutting-edge biomedical research is deployed in an effort to establish racial health equality, rather than to legitimise racial inferiority. At the structural level, these positive intentions are reflected in the aforementioned creation and enforcement of the NIH's inclusion mandate and similar policies established by other federal agencies. ${ }^{10} 11$ While the push for inclusion has had the unintended consequence of creating and justifying racial disparities in medicine on the basis of biological difference, ${ }^{11}$ the underlying premise continues to be one of social and racial justice in medicine and treatment. Similarly, the continued definition and treatment of race as a biogenetic concept is motivated by a belief in the importance of recognising and treating individual differences in health, countering the extant and historical White-centric bias of medicine and genetics. ${ }^{78}$

The individual-level intentions of biomedical researchers seeking racial equality in medicine are equally important to examine, especially given their pivotal role in the validation and reformation of scientific and social thought on the nature of race. As evidenced in Dana Fullwiley's ethnographic work, there are numerous subjective influences on researchers' interpretations of the value attached to race in their analytic models and how they establish the clinical meaningfulness of their results. In fact, many researchers-often having a non-White background-openly acknowledge that their scientific agenda for studying racial disparities in biomedical research serves as a means to advance a personal agenda of reducing racial health disparities at the societal level. Based on interviews and observations collected among researchers in medical genetics laboratories, Fullwiley chronicles the deep, ethical sense of 'duty' experienced by non-White scientists studying the poorer health and severity and impact of diseases on 'their communities'. ${ }^{13}$ By counteracting the white supremacist and racist framing in past studies of race, medicine and health, researchers view their work as a form of affirmative action; their goal is to 'rely on good science and hard data to include minorities in medicine, not to advance an unjust agenda' and identify the appropriate biomedical solutions. ${ }^{13}$ Likewise, this justice-oriented agenda becomes a way to assert that sociocultural factors-such as diet or unhealthy behaviours, ostensibly specific to a given race/ethnic group—are not to blame either, as a genetic basis for poor health or response to medicine is free of moral judgement.

Even when biomedical researchers acknowledge that a biological understanding or race may be inaccurate, the desire to stimulate positive change is sufficient to rationalise the use of race in biomedical research as vital to the broader goal of addressing racial disparities. One researcher invokes what is best described as an intuitive sense of race as biological (based on his research and interaction with patients) in explaining the 'responsibility' of researchers-'as physician-scientists [and] as members of the population'-to continue the study of minority populations and the genetic origins of disparities. ${ }^{13}$ Yet, absent a full understanding of biological mechanisms, these physician-scientists maintain that wholly ignoring race would be 'premature' and 'negligent', ${ }^{13}$ as the knowledge gained from biomedical research is useful for understanding differences in population health. However, the usefulness of race does not justify its meaningfulness and the implications this meaning has for scientific and social knowledge.

\section{A surrogate for future research}

As Hacking contends, the usefulness of clinical knowledge rests on the ability for this knowledge to be put into practice; for example, racially tailored medications, such as BiDil, are only useful insofar as they help treat a specific disease within a specific race. ${ }^{87}$ Although the effectiveness of BiDil, and similar drugs, among Black adults continues to be misconstrued as evidence in favour a biogenetic essentialist view on race, the usefulness of pharmacogenomics reveals nothing about the meaning of race in biomedical research and the causal pathways through which it contributes to racial variation in outcomes. Meaningfulness is similarly imposed on race through the aforementioned process of treating it as a surrogate or proxy variable for yet-to-be determined biological mechanisms. As another example of researchers' fundamentally 'good' and optimistic intentions for their research-anticipating future innovations that help explain and reduce racial differences-recent studies of the 'framing' of race in research describe this anticipatory quality to its use as a surrogate. ${ }^{32} 63$ Researchers' arguments for the utility of race often hinge on the premise of 'imminent medical progress'; 
they concede that race categories a crude marker of biological difference while also being 'useful in the meantime, until the actual genetic variation itself is identified'... at which point '[d]iagnosis and treatment will then the appropriately tailored to the fit genetic variations on an individual basis'. ${ }^{32}$ Thus, at the very least race allows researchers to demarcate 'potentially meaningful' findings. ${ }^{32}$

This forward-looking approach to using and defining race provides a convenient way to simultaneously establish its usefulness and meaningfulness. Usefulness is readily demonstrated through the documentation of racial differences in biomedical research and the subsequent use of racially specific treatments as a solution. Meaningfulness, however, takes on a prospective quality, as race in the present takes on the hypothetical biogenetic origins that scientists expect to uncover in a not-too-distant future. Both qualities of race are valuable to 'well-intentioned' researchers, as they seek to locate solutions to racial disparities in health and medicine within the bounds of biomedicine. Thus, while problematic, an essentialist view of race simplifies the problem of addressing poor health among racial minorities by offering a clear point of individualised biomedicalised intervention, in contrast to the more complex task of changing the socioenvironmental determinants of racial health inequality.

Most importantly, the specific meaning to race and racial disparities established by biomedical research has further-reaching consequences than the particular medical/health phenomenon, condition or disease of interest in a given study. Scholars are increasingly vocal in their concern that searching for the biogenetic origins of medical conditions undermines the well-established understanding of health as a social phenomenon. ${ }^{46}$ 90-92 Accepting race as a surrogate for fundamental biogenetic differences across groups diminishes the importance of social determinants of health extensively documented in the social sciences. This may give rise to arguments suggesting that the fundamental causes of health (eg, racism and socioeconomic status ${ }^{93}{ }^{94}$ ) only appear to be 'fundamental' because we lack knowledge of more upstream, biogenetic causes of health disparities. Consequently, rather than focusing efforts on structural reforms that address these social processes-for example, systemic racism in the form of workplace discrimination, mass incarceration, residential segregation, barriers to education, healthcare inequality ${ }^{95-98}$ the emphasis shifts to biomedical solutions and innovations. While social determinants are not entirely ignored or rendered trivial, the unspoken implication is that that addressing health disparities at the biogenetic level provides a more comprehensive solution. However, Epstein, ${ }^{11} \mathrm{Lee}^{22}$ and Braun ${ }^{21}$ are quick to note that we have as much to learn about social determinants of health as emergent biogenetic causes; moreover, overemphasising the latter explanations may come at the expense of better addressing the former.

While biomedicine is cognizant of issues surrounding the meaning race as a variable, ${ }^{62-70}$ much of the work rests on the assertion that meaning will emerge given sufficient time for research to uncover the biogenetic mechanisms underlying race. ${ }^{11} 1244$ The argument for race as a surrogate is we don't know what we don't know when it comes biogenetics, race and medicine; thus there is no harm in having race temporarily bear the burden of this 'unknown' unknown. However, if biomedical research is entirely predicated on the assumption that racial disparities in health and medicine will be resolved through future knowledge of biogenetic pathways, then that is the direction where researchers will steer their work in the hopes of finding confirmatory results. Therein lies the danger of the essentialist view of race in biomedical research; rather than deductive, the research process becomes deterministic in promoting a social and scientific narrative that reifies racial disparities as a consequence of genetic deficiencies.

\section{CONCLUSION: TOWARDS STRUCTURAL COMPETENCY}

Despite the exponential rate of change and progress in scientific and technological knowledge, the persistence and power of the essentialist framework for race in biomedical research remains an important and consequential conceptual challenge. As examined in this paper-and many insightful social and historical accounts $^{1025-29}$-essentialist thinking is multifactorial and cumulative; it is the product of many and diverse social, cultural, political and economic forces acting on researchers and the work that they produce. Though these forces change and evolve over time, they continue driving towards the same biogenetic mechanisms underlying racial disparities in health and medicine. Crucially, essentialism is not an individualised phenomenon arising from biomedical researchers' intentions to impose a racist agenda on science and thus help to perpetuate White supremacy and Black inferiority at the social level. On the contrary, researchers' personal agendas for research, along with inclusion mandates imposed by federal agencies and the mission statement of 'personalised medicine', are driven by a desire to redress historical wrongs in the scientific study of minority groups, as part of a broader effort to recognise individuals' health needs and eliminate racial disparities in disease and medical treatment. ${ }^{10} 111332$ Though this push for inclusion often carries a substantial social cost- in preserving and possibly further reifying perceptions of race as a biogenetic and immutable-one would be remiss to neglect acknowledging the desire for social and racial justice motivating this work.

However, the interplay between the social and individual-level factors influencing research, and their influence on the creation of knowledge about race and health, speaks to the broader challenge of understanding structure and agency as competing forces within biomedicine. Individual researchers' decisions and actions are constrained by disciplinary and social structures defining the knowledge valued under the umbrella of biomedical research; the reflexive and collective actions and beliefs of individual scientists help to further crystallise these norms. And yet, as noted by sociologists writing on the structure-agency dyad in society, agency is not entirely absent. ${ }^{99}$ Researchers are actors who retain autonomy over the design of their studies and in their presentation of results, especially in their decision to adopt a specific view of race. Hacking's looping effects framework demonstrates how these individual actions-that is, displays of agency - are integral to the legitimisation and creation of social and scientific knowledge. ${ }^{23}$ Granted sufficient time and epistemological momentum, biomedical researchers' reinterpretation and use of race as a social construct can become magnified to challenge and displace assumptions about its biogenetic origins.

Beyond exclusively treating this 'paradigm shift' in biomedicine's conceptualisation of race as an abstract possibility, I conclude by offering a practical discussion of how such a change may be initiated. In keeping with the optimistic and forward-looking agenda shared by many scientists, I argue that the discord between an essentialist and constructivist view on race in biomedical research has a resolvable solution, mutually beneficial to scholars on both sides of the biogenetic and social science divide. Namely, while biomedical and social-historical researchers approach issues surrounding race, genetics and medicine from very different analytical and theoretical perspectives, the reduction of disparities is a shared and strongly desired 
outcome for both parties. To this end, biomedical research-as both a field of study and as individual scientists-should be empowered to be more ambitious and outright in its discussion of the socioenvironmental factors that help explain racial variation in health and medicine.

I premise this argument in the counterfactual scenario that socioeconomic status, rather than race, was used to designate protected groups requiring greater inclusion and attention in research protocols on the basis of social rather than biological or genetic differences. ${ }^{11}$ While not framed in such terms, we see early recognition of this need to redefine inclusion and diversity in the NIH's planned All of Us study, which 'seeks to extend precision medicine to all diseases by building a national research cohort of one million or more US participants' from different racial and ethnic backgrounds and levels of income and education. ${ }^{100}$ Though All of Us continues to prioritise racial and ethnic diversity in recruitment, more directly acknowledging the under-representation of lower-socioeconomic status individuals in biomedical and clinical studies is an important signifier of how biased our knowledge may be; when education, income and wealth-and other measures of socioeconomic status-are excluded from or poorly represented in biomedical research, race is as much a proxy for these socioenvironmental factors as it is for any unexplained genetic variation.

The broader implications of greater attention to social causality in biomedical research are significant. There is valuable narrative power in a pharmacological study finding racial disparities in drug effectiveness and presenting these results as evidence of how socioenvironmental forces inhibit racial equity in the ability of the most promising and advanced medicines to improve individuals' health. This result directly challenges essentialist assumptions underlying racial differences in medical efficacy and the manifestation of disease, as it emerges from within the same body of biomedical research. Indirect challenges to essentialism-premised on minimising the role of genetic factors and promoting social conditions, such as neighbourhood segregation or wage discrimination-are important as well, but do not explicitly refute assumptions about biogenetic mechanisms. Research finds that many non-White individuals are already suspicious of racially tailored pharmaceuticals and treatment or use the idea of genetically preordained, racialised diseases as an explanation for unhealthy behaviours. ${ }^{75}$ Consequently, questioning and/or disproving biogenetic assumptions about the immutable role of race in medicine and health is critical for preventing the adoption of fatalistic and deterministic views towards health among minority groups.

Ultimately, while there continues to be substantial 'boundary-work' in scientific research where disciplinary norms enforce limits on biomedical researchers' freedom to discuss the social implications of their research, ${ }^{15} 78101$ the continued balkanisation of how health disparities are framed in the social scientific and biomedical disciplines inhibits the shared goal of studying and reducing racial disparities. Humanities and social science scholars should not view biomedical researchers' invocation of social determinants as an act of disciplinary encroachment; rather, a more socially conscientious discussion of biomedical research reaffirms the value of a humanities- oriented and social science-oriented approach to health disparities as it helps inform biomedical scholarship. Giving biomedical researchers the opportunity to apply constructivist perspectives on race in their own work helps to promote narratives that embed disparities at the societal, rather than individual level and thus steer solutions in the same systemic and structural direction.
Along these lines, structural competency-that is, the conceptualisation of inequalities in heath 'in relation to the institutions and social conditions that determine health related resources ${ }^{102}$ - is increasingly promoted among medical students and practitioners, especially in a clinical setting. Emphasising the need for health professionals to 'think about how such variables as race, class, gender, and ethnicity are shaped... by the larger structural contexts in which their interactions take place' and to 'recognize how social and economic determinants, biases, inequities and blind spots shape health and illness long before' patients interact with doctors, ${ }^{102}$ the same principles can and should be applied to the biomedical researchers creating and legitimising the biomedical knowledge and interventions that physicians use in clinical encounters. Rather than treating this push for structural competency as a challenge to the biomedical paradigm, empowering biomedical researchers to more freely discuss structural factors is a more amicable solution that recognises their autonomy in striving for racial justice through their work. Seeing as most discussions of biogenetic mechanisms underlying racial variation are already highly speculative, ${ }^{30} 3255$ there is no reason that this biomedical speculation should be exclusively informed by an essentialist view of race.

The debate thus comes full circle to the ongoing discussion of racial profiling in medicine and the utility of relying on these biomedically informed, speculative relationships between race and disease or medical treatment to inform researchers' and practitioners' perceptions of study participants and patients. Despite racial profiling having a negative connotation in virtually all other institutional settings (eg, criminal justice, employment), many medical practitioners maintain that ignoring a patient's race is unnecessary and potentially irresponsible, as race constitutes a critical source of information about their social and demographic background that might prove valuable in their care. ${ }^{103-106}$ Though there is a broad consensus that racial categories are ill-defined (if not undefined entirely) in medical practice, scholars argue that the 'risk of undervaluing the great diversity... among persons within groups... needs to be weighed against the fact that in epidemiologic and clinical research, racial and ethnic categories are useful for generating and exploring hypotheses about environmental and genetic risk factors... for important medical outcomes'. ${ }^{107}$

At issue is the extant focus on the genetic, rather than environmental risk factors in biomedical research, as a socially informed treatment of race and more expansive definition of social diversity in medical research and medicine has substantial value. ${ }^{17} 18$ By recognising the embeddedness of social determinants of health within the socially constructed categories of race used in biomedicine, this research can be used to advance social and scientific knowledge of how social and structural forces contribute to racial health disparities. In this way, treating race as a proxy or surrogate for unexplained variation is a key strength, provided we are cognizant of what this variation means. Race captures the 'social' and 'embodied' experience of being a member of a minority group; it is dense with all of the stress, fear, disrespect, hatred and many other psychosocial and somatic traumas that can influence and intersect with individuals' health and response to treatment. ${ }^{17}{ }^{18}$ If biomedical researchers aspire to fulfil the mandate of truly 'personalised' medicine, they stand to benefit from understanding the individuality of this racialised experience and the need to adequately account for the interaction of biological processes and social environments. The goal is then not to abandon the use of race in biomedical research but to expand the meanings that we imbue it with in order to leverage the entirety of social and scientific knowledge in eliminating racial health disparities. 
Correction notice This article has been corrected since it was published Online First. Funding information has been updated.

Funding This research received support from the Population Research Training grant (T32 HD007168) and the Population Research Infrastructure Program (P2C HD050924) awarded to the Carolina Population Center at The University of North Carolina at Chapel Hill by the Eunice Kennedy Shriver National Institute of Child Health and Human Development.

Competing interests None declared.

Patient consent Not required.

Provenance and peer review Not commissioned; externally peer reviewed.

(c) Article author(s) (or their employer(s) unless otherwise stated in the text of the article) 2019. All rights reserved. No commercial use is permitted unless otherwise expressly granted.

\section{NOTES}

1. As noted by Kahn and others, ${ }^{11} 1246$ this study itself became misappropriated as evidence to support the validity of racially based pharmacogenics. Various news media sources cited the existence of these 29 different medications without including the caveat that these claims racial efficacy are largely unsubstantiated.

2. Further, Catherine Lee's and Shanawani et al's reviews of the use of race in biomedica research publications finds that the majority of researchers provide no explanation for racial differences observed in their studies or suggest that specific biological and/or genetic mechanisms — and, rarely, socioenviromental factors — related to race are at play without pursuing additional testing or validation. ${ }^{4261}$

\section{REFERENCES}

1 Dressler WW, Oths KS, Gravlee CC. Race and ethnicity in public health research: Models to explain health disparities. Annu Rev Anthropol 2005;34:231-52.

2 Braveman P. Health disparities and health equity: concepts and measurement. Annu Rev Public Health 2006:27:167-94.

3 Byrd WM, Clayton LA. An American health dilemma: a medical history of African Americans and the problem of race: beginnings to 1900. New York: Routledge, 2012.

4 Williams DR, Mohammed SA. Racism and health I: pathways and scientific evidence. American Behavioral Scientist 2013;57:1152-73.

5 Centers for Disease Control and Prevention. Health, United States, 2015 with special feature on racial and ethnic health disparities. Atlanta, GA: US Department of Health and Human Services, National Center on Health Statistics, 2016

6 Olshansky SJ, Antonucci T, Berkman L, et al. Differences in life expectancy due to race and educational differences are widening, and many may not catch up. Health Aff 2012:31:1803-13.

7 Jordan WD. White over black: American attitudes toward the Negro, 1550-1812. Chapel Hill: UNC Press Books, 2013.

8 Lindemann M. Medicine and society in early modern Europe. Cambridge: Cambridge University Press, 2010.

9 Chapman A. Astrological medicine. Webster C, ed. Health, medicine and mortality in the sixteenth century. Cambridge: Cambridge University Press, 1979.

10 Washington HA. Medical apartheid: The dark history of medical experimentation on Black Americans from colonial times to the present. New York: Doubleday Books, 2006.

11 Epstein S. Inclusion: The politics of difference in medical research. Chicago: University of Chicago Press, 2008.

12 Kahn J. Race in a bottle: The story of BiDil and racialized medicine in a post-genomic age. Columbia: Columbia University Press, 2013.

13 Fullwiley D. The biologistical construction of race: 'admixture' technology and the new genetic medicine. Social Studies of Science 2008;38:695-735.

14 Fofana MO. The spectre of race in American medicine. Med Humanit 2013;39:13741.

15 Morning A. The nature of race: How scientists think and teach about human difference. California: University of California Press, 2011.

16 Chen M-L. Ethnic or Racial Differences Revisited. Clin Pharmacokinet 2006;45:95764.

17 Krieger N. The science and epidemiology of racism and health: racial/ethnic categories, biological expressions of racism, and the embodiment of inequality an ecosocial perspective. In: Whitmarsh I, Jones DS, eds. What's the use of race? Modern governance and the biology of difference. Cambridge, Massachusetts: The MIT Press, 2010:225-55.

18 Krieger N. Stormy weather: race, gene expression, and the science of health disparities. Am J Public Health 2005:95:2155-60.

19 Sankar P, Cho MK, Condit CM, et al. Genetic research and health disparities. JAMA 2004;291:2985-9.

20 Braun L, Fausto-Sterling A, Fullwiley D, et al. Racial categories in medical practice: how useful are they? PLoS Med 2007;4:e271-28.
21 Braun L. Race, ethnicity, and health: can genetics explain disparities? Perspect Biol Med 2002:45:159-74.

22 Lee SS. Racializing drug design: implications of pharmacogenomics for health disparities. Am J Public Health 2005:95:2133-8.

23 Hacking I. Kinds of people: moving targets. Proceedings of the British Academy 2006;151:285-318.

24 Dennis RM, Darwinism S. scientific racism, and the metaphysics of race. Journal of Negro Education 1995:64:243-52.

25 Painter NI. The history of white people. New York: WW Norton \& Company, 2010.

26 Brandt AM. Racism and research: the case of the Tuskegee Syphilis Study. Hastings Cent Rep 1978:8:21-9.

27 Jones JH. Bad blood. New York: Simon and Schuster, 1993.

28 Anderson W. Colonial pathologies: American tropical medicine, race, and hygiene in the Philippines. Duke: Duke University Press, 2006

29 Hatch AR. Blood sugar: racial pharmacology and food justice in Black America. Minnesota: University of Minnesota Press, 2016

30 Whitmarsh I, Jones DS. Governance and the uses of race. In: Whitmarsh I, Jones DS, eds. What's the use of race? Modern governance and the biology of difference. Cambridge, Massachusetts: The MIT Press, 2010123.

31 Friedman A, Lee C. Producing Knowledge about Racial Differences: Tracing Scientists Use of "Race" and "Ethnicity" from Grants to Articles. The Journal of Law, Medicine \& Ethics 2013:41:720-32.

32 Hunt LM, Megyesi MS. Genes, race and research ethics: who's minding the store? J Med Ethics 2008:34:495-500.

33 Ginsburg GS, Willard HF. Genomic and personalized medicine: foundations and applications. Trans/ Res 2009:154:277-87.

34 Guttmacher AE, McGuire AL, Ponder B, et al. Personalized genomic information: preparing for the future of genetic medicine. Nat Rev Genet 2010;11:161-5.

35 Omenn GS. From human genome research to personalized health care. Issues in Science and Technology 2009:25:51-6.

36 Collins FS, Green ED, Guttmacher AE, et al. US National Human Genome Research Institute. A vision for the future of genomics research. Nature 2003:422:835-47.

37 Hamburg MA, Collins FS. The Path to Personalized Medicine. N Engl J Med Overseas Ed 2010;363:301-4

38 Khoury MJ, Gwinn M, Yoon PW, et al. The continuum of translation research in genomic medicine: how can we accelerate the appropriate integration of human genome discoveries into health care and disease prevention? Genet Med 2007:9:665-74

39 Siest G, Benachour $H_{1}$ Lambert $D$, et al. Functional genomics towards personalized healthcare. Per Med 2009;6:19-32.

40 Sadee W. Drug therapy and personalized health care: pharmacogenomics in perspective. Pharm Res 2008;25:2713-9

41 Collins FS, Varmus H. A new initiative on precision medicine. N Engl J Med Overseas Ed 2015:372:793-5.

42 Lee C. "Race" and "ethnicity" in biomedical research: how do scientists construct and explain differences in health? Soc Sci Med 2009:68:1183-90.

43 Frank R. What to make of it? The (Re)emergence of a biological conceptualization of race in health disparities research. Soc Sci Med 2007:64:1977-83.

44 Braun L. Reifying human difference: the debate on genetics, race, and health. Int J Health Serv 2006:36:557-73.

45 Lee $\mathrm{SS}$. The ethical implications of stratifying by race in pharmacogenomics. Clin Pharmacol Ther 2007:81:122-5.

46 Coote JH, Joyner MJ. Is precision medicine the route to a healthy world? The Lancet 2015;385:1617

47 Tate SK, Goldstein DB. Will tomorrow's medicines work for everyone? Nat Genet 2004;36:S34-42

48 Hungerford C, Kench P. Standards and Standardization. In: Kennedy M, Billett S, Gherardi S, eds. Practice-based Learning in Higher Education. Dordrecht: Springer, 2015:65-83.

49 Frank R. Back to the future? The emergence of a geneticized conceptualization of race in sociology. Ann Am Acad Pol Soc Sci 2015:661:51-64.

50 Morning $A$. And you thought we had moved beyond all that: biological race returns to the social sciences. Ethn Racial Stud 2014;37:1676-85.

51 Caulfield T, Fullerton SM, Ali-Khan SE, et al. Race and ancestry in biomedical research: exploring the challenges. Genome Med 2009;1:8.

52 Foster MW. Looking for race in all the wrong places: analyzing the lack of productivity in the ongoing debate about race and genetics. Hum Genet 2009:126:355-62.

53 Fullwiley D. Race and genetics: attempts to define the relationship. Biosocieties 2007:2:221-37.

54 Bonham VL, Callier SL, Royal CD. Will Precision Medicine Move Us beyond Race? N Engl J Med 2016:374:2003-5.

55 Collins FS. What we do and don't know about 'race', 'ethnicity', genetics and health at the dawn of the genome era. Nat Genet 2004;36:S13-15.

56 Royal CD, Dunston GM. Changing the paradigm from 'race' to human genome variation. Nat Genet 2004;36:S5-7.

57 Yudell M, Roberts D, DeSalle R, et al. Taking race out of human genetics. Science 2016:351:564-5 
58 Tsai J, Ucik L, Baldwin N, et al. Race Matters? Examining and Rethinking Race Portrayal in Preclinical Medical Education. Acad Med 2016;91:916-20.

59 Kahn J. Science Is Complex-So Is Race. Am J Bioeth 2017;17:56-8.

60 Kahn J. Genes, race, and population: avoiding a collision of categories. Am J Public Health 2006;96:1965-70.

61 Shanawani H, Dame L, Schwartz DA, et al. Non-reporting and inconsistent reporting of race and ethnicity in articles that claim associations among genotype, outcome, and race or ethnicity. J Med Ethics 2006;32:724-8.

62 Fujimura JH, Rajagopalan R. Different differences: the use of 'genetic ancestry' versus race in biomedical human genetic research. Soc Stud Sci 2011:41:5-30.

63 Hunt LM, Megyesi MS. The ambiguous meanings of the racial/ethnic categories routinely used in human genetics research. Soc Sci Med 2008;66:349-61.

64 Zuberi T, Patterson EJ, Stewart QT. Race, Methodology, and Social Construction in the Genomic Era. Ann Am Acad Pol Soc Sci 2015;661:109-27.

65 Shields $A E$, Fortun M, Hammonds EM, et al. The use of race variables in genetic studies of complex traits and the goal of reducing health disparities: a transdisciplinary perspective. Am Psychol 2005;60:77-103.

66 Foster MW, Sharp RR. Race, ethnicity, and genomics: social classifications as proxies of biological heterogeneity. Genome Res 2002;12:844-50.

67 Sankar P, Cho MK. Genetics. Toward a new vocabulary of human genetic variation. Science 2002;298:1337-8.

68 Sankar P, Cho MK, Mountain J. Race and ethnicity in genetic research. Am J Med Genet A 2007;143A:961-70.

69 Lee SS, Mountain J, Koenig B, et al. The ethics of characterizing difference: guiding principles on using racial categories in human genetics. Genome Bio/ 2008;9:404-4

70 Rotimi CN. Are medical and nonmedical uses of large-scale genomic markers conflating genetics and 'race'? Nat Genet 2004;36:S43-7.

71 Shiao JL, Bode T, Beyer A, et al. The Genomic Challenge to the Social Construction of Race. Sociological Theory 2012;30:67-88.

72 Fujimura JH, Bolnick DA, Rajagopalan $\mathrm{R}$, et al. Clines without classes: How to make sense of human variation. Sociological Theory 2014;32:208-27.

73 Morning A. Does Genomics Challenge the Social Construction of Race? Sociological Theory 2014;32:189-207.

74 Phelan JC, Link BG, Feldman NM. The Genomic Revolution and Beliefs about Essential Racial Differences: A Backdoor to Eugenics? Am Sociol Rev 2013;78:16791.

75 Condit CM, Parrott RL, Bates BR, et al. Exploration of the impact of messages about genes and race on lay attitudes. Clin Genet 2004;66:402-8.

76 Lynch J, Condit CM. Genes and race in the news: a test of competing theories of news coverage. Am J Health Behav 2006;30:125-35.

77 Morning A. "Everyone Knows It's a Social Construct": Contemporary Science and the Nature of Race. Sociol Focus 2007:40:436-54.

78 Anderson W. Teaching 'race' at medical school: social scientists on the margin. Soc Stud Sci 2008:38:785-800.

79 Morning A. Reconstructing race in science and society: biology textbooks, 1952 2002. AJS 2008:114 Suppl(S1):S106-S137.

80 Donovan BM. Playing with fire? The impact of the hidden curriculum in school genetics on essentialist conceptions of race. J Res Sci Teach 2014;51:462-96.

81 Outram SM, Ellison GT. Improving the use of race and ethnicity in genetic research: a survey of instructions to authors in genetics journals. Science Education 2006;29:78-81.

82 Smart A, Tutton R, Ashcroft R, et al. Can Science Alone Improve the Measurement and Communication of Race and Ethnicity in Genetic Research? Exploring the Strategies Proposed by Nature Genetics. Biosocieties 2006;1:313-24.
83 Outram SM, Ellison GT. Anthropological insights into the use of race/ethnicity to explore genetic contributions to disparities in health. J Biosoc Sci 2006;38:83102.

84 Rabinow P. Artificiality and enlightenment: from sociobiology to biosociality. Blackwell Publishing: Oxford, 2005.

85 Rose N. The politics of life itself: biomedicine, power, and subjectivity in the twentyfirst century. Princeton: Princeton University Press, 2009.

86 Hacking I. Genetics, biosocial groups \& the future of identity. Daedalus 2006;135:81-95.

87 Hacking I. Why race still matters. Daedalus 2005;134:102-16.

88 Kuhn TS. The structure of scientific revolutions. Chicago: University of Chicago Press, 2012.

89 Popper K. Conjectures and refutations: the growth of scientific knowledge. New York: Routledge, 2014.

90 Bayer R, Galea S. Public Health in the Precision-Medicine Era. N Engl J Med Overseas Ed 2015;373:499-501

91 Khoury MJ, Evans JP. A public health perspective on a national precision medicine cohort: balancing long-term knowledge generation with early health benefit. JAMA 2015:313:2117-8.

92 Khoury MJ, Iademarco MF, Riley WT. Precision Public Health for the Era of Precision Medicine. Am J Prev Med 2016;50:398-401.

93 Phelan JC, Link BG. Is racism a fundamental cause of inequalities in health? Annu Rev Sociol 2015;41:311-30.

94 Link BG, Phelan J. Social conditions as fundamental causes of disease. J Health Soc Behav 1995;35:80-94

95 Feagin J, Bennefield Z. Systemic racism and U.S. health care. Soc Sci Med 2014; 103:7-14

96 Pager D, Shepherd H. The Sociology of Discrimination: Racial Discrimination in Employment, Housing, Credit, and Consumer Markets. Annu Rev Sociol 2008;34:181-209.

97 Quillian L. New approaches to understanding racial prejudice and discrimination. Annu Rev Sociol 2006;32:299-328.

98 Reskin B. The race discrimination system. Annu Rev Sociol 2012;38:17-35.

99 Sewell, WH. A theory of structure: duality, agency, and transformation. Am J Sociol 1992;98:1-29.

100 All of Us Research Program. National Institutes of Health. https://allofus.nih.gov/.

101 Gieryn TF. Boundary-Work and the Demarcation of Science from Non-Science: Strains and Interests in Professional Ideologies of Scientists. Am Sociol Rev 1983;48:78195.

102 Metzl JM, Hansen H. Structural competency: theorizing a new medical engagement with stigma and inequality. Soc Sci Med 2014;103:126-33.

103 Barr DA. The practitioner's dilemma: can we use a patient's race to predict genetics, ancestry, and the expected outcomes of treatment? Ann Intern Med 2005; 143:80915.

104 Bonham VL, Sellers SL, Gallagher TH, et al. Physicians' attitudes toward race, genetics, and clinical medicine. Genet Med 2009:11:279-86.

105 Bonham VL, Sellers SL, Woolford S. Physicians' knowledge, beliefs, and use of race and human genetic variation: new measures and insights. BMC Health Serv Res 2014; $14: 456$.

106 Snipes SA, Sellers SL, Tafawa AO, et al. Is race medically relevant? A qualitative study of physicians' attitudes about the role of race in treatment decision-making. BMC Health Serv Res 2011;11:183.

107 Burchard EG, Ziv E, Coyle N, et al. The importance of race and ethnic background in biomedical research and clinical practice. N Eng/ J Med 2003;348:1170-5. 